\section{Psychometric Properties of the Psychological Vulnerability Scale in Higher Education Students}

\author{
Maria José Nogueira', Luisa Barros², and Carlos Sequeira ${ }^{3}$
}

Journal of the American Psychiatric

Nurses Association

$1-8$

(C) The Author(s) 2017

Reprints and permissions:

sagepub.com/journalsPermissions.nav DOI: $|0.1| 77 / 10783903 \mid 769526$

japna.sagepub.com

(s)AGE

\begin{abstract}
BACKGROUND: Psychological vulnerability is related to cognitive beliefs that reflect dependence on one's sense of self-worth and to maladaptive functioning. It is a disadvantage that renders people less protected to face negative life experiences. OBJECTIVE: The purpose of this study was to adapt and test the psychometric properties of the Psychological Vulnerability Scale in a sample of 267 Portuguese higher education students. DESIGN: A psychometric study of the Psychological Vulnerability Scale, after translation into Portuguese, was performed with a convenience sample of higher education students. Participants were asked to fill in the sociodemographic questionnaire, the Psychological Vulnerability Scale, the Brief Symptom Inventory, and a one-item question about the Perception of Vulnerability. RESULTS: The mean age of the participants was 20.5 years $(S D=3.3)$. A factor analysis confirmed the original onefactor structure, explaining $42.9 \%$ of the total variance. The Psychological Vulnerability Scale showed adequate internal consistency and excellent test-retest stability. Convergent validity was confirmed by positive correlations with the Brief Symptom Inventory and Perception of Vulnerability. CONCLUSIONS: Overall, the Psychological Vulnerability Scale showed good validity, reliability, and stability over time. The Psychological Vulnerability Scale is now ready to be used by practitioners and researchers to measure the psychological vulnerability among Portuguese higher education students. These data add to the body of knowledge of psychiatric and mental health nursing and provides support for the use of the Psychological Vulnerability Scale in higher education students.
\end{abstract}

\title{
Keywords
}

psychological vulnerability, psychological vulnerability scale, reliability, higher education students

Psychological vulnerability is a "pattern of cognitive beliefs reflecting a dependence on achievement or external sources of affirmation for one's sense of self-worth" (Sinclair \& Wallston, 1999, p. 120), related to maladaptive functioning. Maladaptive cognitive reactions to interpersonal events can affect coping behaviors, interpersonal relationships, and psychological and physical well-being. Recent research with higher education students show that psychological vulnerability is negatively correlated with adaptive constructs (S. Satici, 2016; S. Satici \& Uysal, 2016; S. Satici, Uysal, Yilmaz, \& Deniz, 2015) and positively correlated with negative health outcomes (Akin, 2014; B. Satici, Saricali, Satici, \& Çapan, 2014; S. Satici \& Uysal, 2016; Uysal, 2015). Maladaptive cognitive patterns have been pointed out as a significant risk factor for depressive symptoms in higher education students (Proag, 2014; Young, LaMontagne, Dietrich, \& Wells, 2012). However, the psychological vulnerability has not yet been studied in Portuguese higher education students. Practitioners and researchers need accurate and reliable measurement instruments to assess the psychological vulnerability, in order to find and provide adequate preventive solutions to increase students' mental health (S. Satici, 2016; S. Satici \& Uysal, 2016).

\section{Psychological Vulnerability}

The psychological vulnerability construct refers to a cognitive structure that makes individuals more fragile under stress conditions, assuming that some people are more affected by stressful events than others (Sinclair \& Wallston, 1999, 2010). According to Sinclair and Wallston

\footnotetext{
'Maria José Nogueira, RMHN, Lisbon University and Lisbon School of Nursing, Lisbon, Portugal

${ }^{2}$ Luisa Barros, PhD, Lisbon University, Lisbon, Portugal

${ }^{3}$ Carlos Sequeira, RMHN, PhD, Porto School of Nursing, and research at the Center for Health Technology and Services Research (CINTESIS), Porto, Portugal
}

\section{Corresponding Author:}

Maria José Nogueira, Lisbon School of Nursing, Lisbon, Portugal.

Email: nogueira.mjc@gmail.com 
(1999), the psychological vulnerability is a form of cognitive vulnerability related to dependence, perfectionism, and need to be approved by external sources. It is a disadvantage that renders people less protected when facing an array of negative life experiences, more dependent, and susceptible to anxiety, depression, and psychological breakdown (Haeffel \& Hames, 2014; Meins et al., 2012; Sinclair \& Wallston, 1999).

Researchers have investigated various links between cognitive vulnerability and psychological breakdown, mainly depression (Haeffel et al., 2008; Sinclair \& Wallston, 2010). Beck focused on the role of dysfunctional attitudes (Beck, 1987) or maladaptive cognitions (i.e., rigid, global negative thinking and automatic negative thoughts about the self, the world, and the future) in promoting depression (Beck \& Haigh, 2014). Hewitt and Flett (1991) discuss that overall perfectionism is significantly associated with psychological distress. Selforiented perfectionists strive for flawlessness, set excessively high personal standards of performance accompanied by overly critical evaluation of one's own behavior (Stoeber, 2014). In addition, self-criticism and dependence (Blatt, 2008) are frequent in depression. Selfcriticism configures inferiority, guilt, feeling of harsh self-scrutiny, and unworthiness. Self-critics struggle for excessive achievement, have a huge fear of disapproval, and experience less perceived support (Moroz \& Dunkley, 2015). Similarly, dependence is the self-perception of being unprotected, powerless, unable to function adequately without the help of others, and the feeling of weakness. Dependent people fear to be rejected, abandoned, and are overly dependent on social feedback for gratification (Beck \& Haigh, 2014).

These vulnerability dispositions lead to conditions of personal disadvantage, such as dependence on others' approval for their sense of self-worth and negative thinking disposition about inner attributes, which is the opposite to believe in oneself and positive self-esteem (Sinclair \& Wallston, 1999, 2010). Aday (1994) defines vulnerable populations as being at risk for psychological and/or social health and more vulnerable to suffer from health problems, harm, or neglect. Psychologically vulnerable individuals tend to overreact to minor stressful events and are more susceptible to stress (Abramson, Metalsky, \& Alloy, 1989).

Previous literature on psychological vulnerability in adult samples indicated that it was negatively associated with adaptive constructs such as resilient coping, positive affect, social support, life satisfaction dispositional optimism, and self-efficacy (Sinclair \& Wallston, 1999), and positively associated with negative affect, perceived helplessness, maladaptive coping behavior, and depressive symptoms (Sinclair \& Wallston, 1999, 2010). Also, it is also found to be a positive predictor of alexitimia and a negative predictor of heath behaviors and well-being (Rueda, Perez-Garcia, Sanjuan, \& Ruiz, 2007).

In college students, recent research shows that psychological vulnerability may constitute a negative predictor of resilience and subjective well-being (S. Satici, 2016). Negative correlations have been found with adaptive constructs such as social competence (B. Satici et al., 2014), subjective happiness (S. Satici \& Uysal, 2016), life satisfaction, social safeness, positive affect, flourishing, and hope (S. Satici et al., 2015). Conversely, positive relations have been found with negative health outcomes like Facebook addiction (B. Satici et al., 2014), perceived helplessness, self-judgment, overidentification, negative affect, hostility (Akin, 2014; B. Satici et al., 2014; S. Satici \& Uysal, 2016; Uysal, 2015). Thus, it is not surprising that there is increasing interest to study higher education students' psychological vulnerability. This issue is relevant to mental health and research, since maladaptive cognitive patterns have been pointed out as a significant risk factor for depressive symptoms in this population (Proag, 2014; Young et al., 2012).

From the best of our knowledge, there is no specific study on psychological vulnerability related to Portuguese students. Thus, measurement instruments are needed to accurately assess the psychological vulnerability and that can help develop interventions to improve the mental health of higher education students (S. Satici, 2016; S. Satici \& Uysal, 2016).

\section{Specificity of the Psychological Vulnerability Scale}

The Psychological Vulnerability Scale (PVS; Sinclair \& Wallston, 1999) was developed in the United States and was designed to identify vulnerable individuals in adult chronically ill populations. The psychological vulnerability measured by the PVS is a set of six maladaptive cognitive patterns or cognitions that promote harmful reactions to stress, specifically reflecting perceptions related to social dependence, self-oriented perfectionism, criticism, negative attributions, and reliance on external sources of approval (Sinclair \& Wallston, 1999, 2010). According to the authors, this concept comprises interpersonal sensibility, negative thinking over life events, automatic negative thoughts (about oneself, world, and future), and a global rigid function (Beck \& Haigh, 2014; Hankin \& Abramson, 2002).

The original study of the PVS showed adequate internal consistency and stability, and thus, the authors considered this scale to be a reliable and stable instrument (Sinclair \& Wallston 1999, 2010). To date, the PVS has been used in clinical and healthy populations. Subsequent psychometric property tests on PVS, both with community- and hospital-based samples, in the United States 
(Sinclair \& Wallston, 2010), Scotland (Selbie et al., 2004), and Spain (Rueda et al., 2007) consistently showed a unidimensional structure, adequate internal consistency, and stability over time (Sinclair \& Wallston, 2010). The study conducted by Selbie et al. (2004), involving adults, confirmed one relevant factor structure, good internal consistency and moderate test-retest scores, and discriminative power between clinical samples and the general population. These authors considered that the PVS was a reliable instrument for use in the general population (Selbie et al., 2004). The Spanish study (Rueda et al., 2007) also showed good internal consistency, high stability, and confirmed a one-factor structure. The PVS positively predicted alexithymia and negatively predicted health behaviors and well-being (Rueda et al., 2007).

Despite the original purpose of the PVS to screen chronically ill persons, currently there is a growing interest in this scale to measure the psychological vulnerability of students, and this condition has also been addressed as a relevant mental health issue among higher education students, due to the negative relations that have been found with adaptive constructs, and as predictor of negative health outcomes (S. Satici et al., 2015; S. Satici \& Uysal, 2016; Uysal, 2015).

A first study conducted in Turkey with higher education students maintained the original structure (which explained $36 \%$ of total variance) and revealed good internal consistency (Akin \& Eker, 2011). Since then, several studies have provided substantial empirical data to support the psychometric properties of the PVS in college student samples (Akin, 2014; B. Satici et al., 2014; S. Satici, 2016; S. Satici et al., 2015; S. Satici \& Uysal, 2016; Uysal, 2015). So far, there seems to be no developed research that investigates the relationship between psychological vulnerability and the subjective perception of vulnerability, or psychopathological symptoms, in higher education students. Moreover, the PVS has not been translated and adapted to Portuguese.

\section{Purpose}

The purpose of this study was to adapt the PVS to Portuguese and to explore its psychometric properties in a sample of higher education students. Three specific aims were defined: (a) to evaluate the reliability and stability of the PVS, (b) to evaluate the validity of the PVS, and (c) to evaluate the convergent validity of the PVS.

\section{Method}

\section{Study Design}

This study was conducted in two stages. The first step was to culturally adapt the PVS into Portuguese according to standard procedures (see translation protocol). The second stage involved the psychometric validation study of the Portuguese version of the PVS.

\section{Ethical Considerations}

The present study is in accordance with the Declaration of Helsinki. The written informed assent and consent for data collection were obtained from the Institutional Review Board, Ethics Committee of the Health Technology School of Lisbon (ESTeSL), and the authors of this study received authorization to use all the instruments. All participants were previously asked to give a written informed consent before being provided with information on the purpose and implications of the study. All were informed of their right to withdraw from the study at any time.

\section{Sampling and Setting}

Participants were recruited using a convenience sample of undergraduates enrolled in four degree courses of ESTeSL. The inclusion criteria were the following: (a) aged 18 years and older and (b) Portuguese native speakers. Data collection took place in May 2014. During the last 10 minutes of class, all the students attending were invited to participate. Students who agreed to participate were asked to fill in a baseline form with the following measures: sociodemographic topics, the PVS, the Brief Symptom Inventory (BSI), and a one-item question about the Perception of Vulnerability. For data stability analysis, participants were asked once again to fill in the form 5 weeks after baseline measurement. A total of 267 higher education students completed the form with less than $10 \%$ missing data and were included in the final analysis. The majority of participants were women and single, in accordance with national ratios of higher education students (DGEEC \& DSEE, 2014).

\section{Measurements}

The PVS is a self-administered instrument designed to obtain information about psychological vulnerability. It is designed to screen for maladaptive cognitive patterns, such as dependence, perfectionism, need for external sources of approval, and generalized negative attributions. The PVS is a six-item scale (e.g., "I need approval from others to feel good about myself") and each item response is rated with anchors $1=$ does not describe me at all to $5=$ describes me very well (Table 2). Possible total scores range from 6 to 30, with higher scores indicating greater psychological vulnerability. In the original version, Cronbach's $\alpha$ coeffcient ranged from .71 to .87 for different samples, and the test-retest correlation, after 
Table I. Sociodemographic Characteristics of the Participants $(N=267)$.

\begin{tabular}{lrc}
\hline Variable & $n$ & $\%$ \\
\hline Gender & 236 & \\
$\quad$ Female & 31 & 88.4 \\
Male & & 11.6 \\
Marital status & 255 & \\
$\quad$ Single & 12 & 95.5 \\
$\quad$ Other & & 4.5 \\
Cohabitation & \\
$\quad$ Parents & 151 & \\
$\quad$ Relatives, colleagues, or & 102 & 56.6 \\
friends & & 29.6 \\
$\quad$ Alone & 14 & 13.8 \\
Year & & \\
$\quad$ Freshman & 105 & 39.3 \\
Second & 69 & 25.8 \\
$\quad$ Third & 85 & 31.8 \\
Senior & 8 & 3 \\
Course & & \\
$\quad$ Dietetics and Nutrition & 103 & 38.3 \\
Pharmacy & 94 & 35.2 \\
Clinical Analyses & 48 & 18.3 \\
Pathological Anatomy & 22 & 8.2 \\
\hline
\end{tabular}

${ }^{a}$ During school period.

five to six weeks, was $r=.83$, and after a 3-month followup, it was $r=.81$ (Sinclair \& Wallston 1999). With a college sample, Cronbach's $\alpha$ ranged from .65 to .79 (Akin \& Eker, 2011, S. Satici \& Uysal, 2016). Thus, the PVS has been confirmed as a valid, reliable, and stable measure for research purposes involving higher education students (Akin, 2014; S. Satici, 2016; S. Satici et al., 2015; Uysal, 2015) and has the advantage of being a brief measurement instrument.

The BSI (Portuguese version: Canavarro, 1999) assesses psychopathological and emotional disturbances. It is a self-administered questionnaire (53 items), with ratings in a 5 -point Likert-type scale from 0 $=$ never to $4=$ repeatedly. The BSI includes 9 subscales: Somatization; Obsessive-compulsive (impulsive, persistent, unwanted behavior); Interpersonal Sensitivity (feelings of personal inadequacy, inferiority, particularly in comparison with others); Depression (clinical indicators); Anxiety (general indicators); Hostility (thoughts, emotions, behaviors, negative state of anger); Phobic Anxiety (persistent and irrational fear leading to avoidance); Paranoid Ideation (projective thoughts, suspicion, grandiosity, egotism); and Psychoticism (indicators of isolation and schizoid lifestyle, thought control). In addition, the BSI provides three global indices of distress or summary of emotional disturbance assessments: General Index Symptoms (GIS; combining intensity of experienced discomfort with the number of reported symptoms); Positive Symptoms Index (PSI; average intensity of all the symptoms reported), and Total Positive Symptoms (TPS; counting the number of symptomatic complaints). The BSI allows to distinguish emotionally disturbed individuals from nondisturbed individuals, with a cutoff point (PSI $\geq 1.7=$ emotional disturbance). The Portuguese version of the BSI showed adequate levels of internal consistency (Cronbach's $\alpha$ ) and good stability for the nine scales, and it was able to discriminate between clinical and nonclinical samples (Canavarro, 1999). In the current study, Cronbach's $\alpha$ was .95 , and in the subscales it ranged from .68 to .76 (Phobic Anxiety and Depression).

Perception of Vulnerability assesses the students' sense of vulnerability about their mental health state. It is a single subjective question, "Do you feel vulnerable regarding your mental health?" Scoring is on a 5-point rating scale from possible answers $1=$ nothing vulnerable to $5=$ extremely vulnerable, with higher scores indicating a higher perception of vulnerability.

Sociodemographic characteristics: gender, age, marital status, cohabitation, academic year, and course were all evaluated.

\section{Data Analysis}

Data analysis was performed using IBM SPSS Statistics 20 for Windows ${ }^{\circledR}$ (IBM Corporation, Armonk, NY). Participants with more than $10 \%$ data missing were excluded. Factor analysis was performed through a principal component analysis. Reliability analysis test was calculated using Cronbach $\alpha$ coefficients and stability with Spearman correlation. Adequacy test KaiserMeyer-Olkin (KMO) and normality KolmogorovSmirnov test of the sample were performed. We assumed $p<.005$ as level of trust ( $p$ value). In the Pearson correlation analysis used to test the convergent validity, a moderate correlation $(r=.30)$ between variables was considered meaningful. Parametric and nonparametric tests were performed depending on the nature of the distribution of the variables (Marôco, 2011).

\section{Translation and Back-Translation Protocol}

The translation process followed the standard procedures according to international guidelines (Muñiz, Elosua, \& Hambleton, 2013). The first step was to obtain the authors' written permission to use the PVS in Portugal. Then two translations and back-translations were performed by two different native speakers. Semantic equivalence was further conceptually reviewed by a panel of five mental health experts. Using the Thinking Aloud Method (Someren, Barnard, \& Sandberg, 1994), 
Table 2. Descriptive Data and Results of the Analysis ${ }^{a}$ of PVS Items, Eigenvalues, Variance, and Factor Loadings (N=267).

\begin{tabular}{|c|c|c|c|c|c|}
\hline PVS items & M & $S D$ & $\begin{array}{l}\text { Corrected item-total } \\
\text { correlation }\end{array}$ & $\begin{array}{l}\alpha \text { if item } \\
\text { deleted }\end{array}$ & $\begin{array}{l}\text { Factor } \\
\text { loading }\end{array}$ \\
\hline $\begin{array}{l}\text { I. If I don't achieve my goals, I feel like a failure } \\
\text { as a person }\end{array}$ & 3.00 & I.II & .56 & .66 & .75 \\
\hline $\begin{array}{l}\text { 2. I feel entitled to better treatment from others } \\
\text { than I generally receive. }\end{array}$ & 2.25 & 1.07 & .40 & .71 & .59 \\
\hline $\begin{array}{l}\text { 3. I am frequently aware of feeling inferior to } \\
\text { other people. }\end{array}$ & 2.02 & 1.13 & .56 & .66 & .76 \\
\hline $\begin{array}{l}\text { 4. I need approval from others to feel good } \\
\text { about myself. }\end{array}$ & 2.12 & 1.06 & .44 & .70 & .63 \\
\hline $\begin{array}{l}\text { 5. I tend to set goals too high and them become } \\
\text { frustrated trying to reach them. }\end{array}$ & 2.73 & 1.23 & .42 & .70 & .61 \\
\hline $\begin{array}{l}\text { 6. I often feel resentful when others take } \\
\text { advantage of me. }\end{array}$ & 2.97 & 1.25 & .40 & .71 & .58 \\
\hline Eigenvalue & & & & & 2.57 \\
\hline Total variance (\%) & & & & & 42.90 \\
\hline
\end{tabular}

Note. PVS = Psychological Vulnerability Scale.

${ }^{a}$ Extraction method-principal component analysis with Varimax rotation.

to check the acceptability of words and phrases, the pretest conducted with 10 students revealed that the PVS was easily understood. Nevertheless, minor language adjustments were made to best fit the target population.

\section{Results}

\section{Sociodemographic Characteristics of the Participants}

Participants were 18 to 40 years old $(M=20.5 ; S D=3.3)$, mostly women $(88.4 \%)$, single, and more than half lived with their parents. The majority were freshmen, attending dietetics and nutrition. Participants' characteristics are summarized in Table 1.

\section{Measures and Variables}

The mean score of PVS was $15.1(S D=4.5)$, indicating a moderate level of psychological vulnerability. Students in Dietetics and Nutrition reported the highest levels of PVS (16.5). The mean BSI-PSI score was $1.6(\mathrm{SD}=.4)$, below the cutoff point (PSI $\geq 1.7$ ), revealing a non-emotionally disturbed sample. The Perception of Vulnerability (1-5) mean was 2.1 , and more than half $(50.2 \%)$ found themselves "little vulnerable," $24.3 \%$ felt "nothing vulnerable," 17.2\% “moderately vulnerable," 4.9\% "very vulnerable," and only a residual amount (1.5\%) felt "extremely vulnerable." Psychological vulnerability only discriminated differences among courses $\left(F_{3}=8.777 ; p=\right.$ .000). $T$ test showed no significant differences by sex $\left(t_{265}\right.$ $=-1.439, p=.151)$. However, the mean score of PVS was slightly higher in females (15.2 vs. 14).

\section{Validity}

Construct validity was examined by conducting analysis on the PVS items. The results, means, and standard deviations for the six items are displayed in Table 2. The adequacy of the sample was previously determined through the KMO test, which revealed good suitability $(\mathrm{KMO}=$ 0.77) of data for factor analysis. Also, coefficient Bartlett's test of sphericity value was $\chi^{2}(15)=285.103$ $(p<.000)$, which enabled the use of factor analysis. All items showed adequate item-total correlations higher than .30. Principal component analysis was performed, followed by a Varimax orthogonal rotation, both confirming the original one-factor final solution (Table 2).

\section{Reliability and Test-Retest}

Internal consistency was calculated using Cronbach's $\alpha$ and replicability using test-retest. The Total PVS's $\alpha$ was acceptable (.73). Test-retest stability, verified by Pearson correlation coefficients (5-week follow-up measures), showed excellent values $(r=.88, p<.0001)$, ranging from $r=.68$ (Item 2) to $r=.87$ (Item 3).

\section{Convergent Validity}

Bivariate Pearson coefficient correlations were performed with BSI and Perception of Vulnerability as external standard measures for criterion validity, as summarized in Table 3. Results showed a positive, weak to moderate significant $(p<.05)$ correlation with all subscales of BSI and perception of vulnerability $(r=.51 ; p<.0001)$. The BSI correlation ranged from $r=.28$ (Somatization) to $r=.62$ 
Table 3. Correlation of the PVS With Measures of External Criterion $(N=267)$.

\begin{tabular}{lc}
\hline External measures & $\begin{array}{c}\text { Psychological } \\
\text { vulnerability }\end{array}$ \\
\hline BSI subscales & \\
Somatization & $.28^{*}$ \\
Obsessive-Compulsive & $.50^{*}$ \\
Interpersonal Sensibility & $.62^{*}$ \\
Depression & $.60^{*}$ \\
Anxiety & $.48^{*}$ \\
Hostility & $.45^{*}$ \\
Phobic Anxiety & $.32^{*}$ \\
Paranoid Ideation & $.55^{*}$ \\
Psychoticism & $.61^{*}$ \\
BSI indices & \\
GIS (General Index Symptoms) & $.63^{*}$ \\
PSI (Positive Symptoms Index) & $.54^{*}$ \\
TPS (Total Positive Symptoms) & $.45^{*}$ \\
Perception of vulnerability & $.5 I^{* *}$ \\
\hline
\end{tabular}

Note. PVS = Psychological Vulnerability Scale; BSI = Brief Symptom Inventory.

$*_{p}<.001 . * * p<.000$

(Interpersonal Sensitivity). Index correlation values ranged from $r=.54$ (TSP) to $r=.63$ (GSI). As expected, the highest correlations of the PVS were found for Interpersonal Sensitivity $(r=.62 ; p<.001)$, Psychoticism $(r=.61 ; p<.001)$, and Depression $(r=.60 ; p<.001)$. The three indexes of the BSI correlations ranged from the strongest GIS $(r=.63 p<.001)$ to the weakest value TPS $(r=.45, p<.001)$. These results indicate that the PVS construct is positive and moderately related with BSI constructs and with the self-reported Perception of Vulnerability question. The nonparametric MannWhitney $U$ test used to compare the medians of PVS between groups of students (emotional/nonemotionally disturbed) showed statistically significant differences $(U=3003.5 ; W=20208.5 ; p<.0001)$. Emotionally disturbed students showed higher scores of PVS than students without emotional disturbance.

\section{Discussion}

The findings of this study add to a growing body of literature on the measurement of psychological vulnerability by translating and evaluating the psychometric properties of the PVS within Portuguese higher education students. Several important findings emerged from this study.

First, the results successfully confirmed that the PVS is a reliable measurement instrument to be applied to higher education students, showing adequate internal consistency and excellent stability over time. Current Cronbach's alpha remained stable within the range of original and students' samples, which is significant considering the small number of items. Generally, a larger item structure decreases the error of measurement and increases the reliability (Marôco, 2011).

Second, the construct validity of the Portuguese version of the PVS confirms the original six-item unidimensional structure, in accordance with previous literature (Akın, Demirci, \& Y1ldı, 2015; Rueda et al., 2007; B. Satici et al., 2014; Selbie et al., 2004; Sinclair \& Wallston, 1999, 2010).

Third, these study findings add new information about convergent validity between the PVS construct and emotional disturbance and the awareness of being vulnerable (two external negative measures) among higher education students. This relation was demonstrated by the presence of positive correlations with all subscales of the BSI and with the single question about Perception of Vulnerability. The strongest correlations, in accordance to the theoretical framework, were obtained between PVS and BSI GIS, Internal Sensibility, Psychoticism, and Depression subscales, suggesting a link between emotional discomfort experienced; dependence; feelings of personal inadequacy and inferiority; specific negative design thinking and thoughts; lack of self-worth, negative affect, hostility, criticism, and negative attributions; and depression symptoms (Beck \& Haigh, 2014; Sinclair \& Wallston, 1999, 2010; Stoeber \& Corr, 2015). Dependent, self-critics and perfectionists have high dependence on external sources and very stringent standards, due to the intense need to be loved and accepted by others, and the tremendous fear of losing nurturance and of disapproval (Aday, 1994; Sinclair \& Wallston, 2010). Additionally, they tend to experience more negative emotions or distress, greater negative affect, self-judgment, overidentification, and feeling ashamed of their faults (S. Satici \& Uysal, 2016; Stoeber \& Corr, 2015). These outcomes are consistent with previous studies, showing that psychological vulnerability is positively related to maladaptive coping behavior and perceived helplessness (Akin, 2014; Rueda et al., 2007; B. Satici et al., 2014; Selbie et al., 2004; Sinclair \& Wallston, 2010). As expected, moderate values suggest that the PVS measures a particular way of thinking and feeling (Sinclair \& Wallston, 2010) but not the psychopathological symptoms.

Finally, the positive moderate and highly significant correlation between PVS and Perception of Vulnerability provides evidence about the ability of higher education students to recognize their own mental state and to accurately assess psychological vulnerability. We believe that this capacity can be an important feature that can help empower students. It would also be important to explore if the consciousness of being vulnerable can discriminate between students' psychological vulnerability in clinical samples. 
The current study has some limitations that should be considered when interpreting the results. First, data were limited to self-reported measures, which may reduce the internal validity. Second, it is difficult to predict generalizability in clinical samples.

Notwithstanding these limitations, this study offers some novel contribution. The PVS proved to be a valid, reliable, and stable instrument to assess higher education students' psychological vulnerability. Findings add empirical data to better understand this pertinent, yet underexplored mental health issue. Last, because the PVS is a brief measurement scale and is now available in the Portuguese version, it can be widely used by researchers. It is also an efficient measure to support practitioners in monitoring mental health interventions to reduce psychological vulnerability among higher education students.

Further studies need to be carried out in order to provide more definite evidence and to expand the psychometric properties of the Portuguese version of the PVS, namely, to discriminate healthy and unhealthy samples. Monitoring psychometric properties of psychometric tools in different target populations and contexts contributes to more reliable mental health research measures.

\section{Authors' Note}

All the study's procedures complied with the high ethical standards of the Institutional Research Ethics Committee of ESTeSL and with the human subject protection protocol of the Declaration of Helsinki and its later amendments. Also, an e-mail address was provided to the participants for additional clarification, if needed. Participants did not report any adverse reactions.

\section{Author Roles}

All authors contributed equally to the writing of this article.

\section{Declaration of Conflicting Interests}

The author(s) declared no potential conflicts of interest with respect to the research, authorship, and/or publication of this article.

\section{Funding}

The author(s) received no financial support for the research, authorship, and/or publication of this article.

\section{References}

Abramson, L., Metalsky, G., \& Alloy, L. (1989). Hopelessness depression. A theory-based subtype of depression. Psychological Review, 96, 358-372. doi:10.1037/0033295X.96.2.358

Aday, L. (1994). Health status of vulnerable populations. Annual Review of Public Health, 15, 487-509. doi:10.1146/ annurev.pu.15.050194.002415
Akin, U. (2014). The predictive role of the self-compassion on psychological vulnerability in Turkish university students. International Journal of Social Science \& Education, 4, 693-701.

Akın, A., Demirci, İ., \& Yıldız, E. (2015). Personal self-concept as mediator and moderator of the relationship between insight and psychological vulnerability. International Online Journal of Educational Sciences, 7(1), 79-86.

Akin, A., \& Eker, H. (2011, July). Turkish version of the Psychological Vulnerability Scale: A study of validity and reliability. Paper presented at the 32th International Conference of the Stress and Anxiety Research Society (STAR), Münster, Germany.

Beck, A., \& Haigh, E. (2014). Advances in cognitive theory and therapy: The generic cognitive model. Annual Review of Clinical Psychology, 10, 1-24. doi:10.1146/annurevclinpsy-032813-153734

Beck, A. T. (1987). Cognitive models of depression. Journal of Cognitive Psychotherapy, 1, 5-37.

Blatt, S. J. (2008). Polarities of experience: Relatedness and self-definition in personality development, psychopathology, and the therapeutic process. Washington, DC: American Psychological Association.

Canavarro, M. (1999). Brief Symptom Inventory: BSI. A critical review of the studies carried out in Portugal. In R. Simões, C. Machado, M. Gonçalves, \& S. Almeida (Eds.), Psychological Evaluation (pp. 305-330). Braga, Portugal: Quarteto.

DGEEC \& DSEE. (2014). Student Profile 2012/2013. Directorate-General for Education and Science Statistics and Directorate-General for Education Statistics Services. Lisbon, Portugal: Author. Retrieved from http://www. dgeec.mec.pt

Haeffel, G., Gibb, B., Metalsky, G., Alloy, L., Abramson, L., Hankin, B., . . S Swendsen, J. (2008). Measuring cognitive vulnerability to depression: Development and validation of the cognitive style questionnaire. Clinical Psychology Review, 28, 824-836. doi:10.1016/j.cpr.2007.12.001

Haeffel, G. J., \& Hames, J. L. (2014). Cognitive vulnerability to depression can be contagious. Clinical Psychological Science, 2(1), 75-85. doi:10.1177/2167702613485075

Hankin, B. L., \& Abramson, L. Y. (2002). Measuring cognitive vulnerability to depression in adolescence: Reliability, validity, and gender differences. Journal of Clinical Child and Adolescent Psychology, 31, 491-504. doi:10.1207/ S15374424JCCP3104

Hewitt, P., \& Flett, G. (1991). Perfectionism in the self and social contexts: Conceptualization, assessment, and association with psychopathology. Journal of Personality and Social Psychology, 60, 456-470.

Marôco, J. (2011). Statistical analysis with SPSS statistics (5th ed.). Pero Pinheiro, Portugal.

Meins, E., McCarthy-Jones, S., Fernyhough, C., Lewis, G., Bentall, R. P., \& Alloy, L. B. (2012). Assessing negative cognitive style: Development and validation of a short-form version of the Cognitive Style Questionnaire. Personality and Individual Differences, 52, 581-585. doi:10.1016/j. paid.2011.11.026

Moroz, M., \& Dunkley, D. (2015). Self-critical perfectionism and depressive symptoms: Low self-esteem and experiential 
avoidance as mediators. Personality and Individual Differences, 87, 174-179. doi:10.1016/j.paid.2015.07.044

Muñiz, J., Elosua, P., \& Hambleton, R. K. (2013). Guidelines for translation and adaptation of tests ( 2 nd ed). Psicothema, 25, 151-157. doi:10.7334/psicothema2013.24

Proag, V. (2014). The concept of vulnerability and resilience. Procedia Economics and Finance, 18, 369-376. doi:10.1016/S2212-5671(14)00952-6

Rueda, B., Perez-Garcia, A. M., Sanjuan, P., \& Ruiz, M. A. (2007). The psychological vulnerability measurement: Psychometric characteristics and validation in nonclinical population. In P. M Goldfarb (Ed.), Psychological tests and testing research trends (pp. 39-53). New York, NY: Nova Science. doi:978-1-60021-569-8

Satici, B., Saricali, M., Satici, S., \& Çapan, B. (2014). Social competence and psychological vulnerability as predictors of Facebook addiction. Studia Psychologica, 56, 301-308. Retrieved from https://www.researchgate.net/publication/271824827

Satici, S. (2016). Psychological vulnerability, resilience, and subjective well-being: The mediating role of hope. Personality and Individual Differences, 102, 68-73. doi:10.1016/j.paid.2016.06.057

Satici, S., \& Uysal, R. (2016). Psychological vulnerability and subjective happiness: The mediating role of hopelessness. Stress and Health. Advance online publication. doi:10.1002/smi.2685

Satici, S. A., Uysal, R., Yilmaz, M. F., \& Deniz, M. E. (2015). Social safeness and psychological vulnerability in Turkish youth: The mediating role of life satisfaction. Current Psychology, 35(1), 22-28. doi:10.1007/s12144-015-9359-1
Selbie, H., Smith, B. H., Elliott, A. M., Teunisse, S., Chambers, W. A., \& Hannaford, P. C. (2004). A validation of the psychological vulnerability scale and its use in chronic pain. Pain Clinic, 16, 153-162. doi:10.1163/ 156856904774134352

Sinclair, V., \& Wallston, K. (1999). The development and validation of the Psychological Vulnerability Scale. Cognitive Therapy and Research, 23, 119-129. doi:10.1023/A:1018770926615

Sinclair, V., \& Wallston, K. (2010). Psychological vulnerability predicts increases in depressive symptoms in individuals with rheumatoid arthritis. Nursing Research, 59, 140-146. doi:10.1097/NNR.0b013e3181d1a6f6

Someren, M., Barnard, Y., \& Sandberg, J. (1994). The think aloud method. A practical guide to modelling cognitive processes. London, England: Academic Press.

Stoeber, J. (2014). Multidimensional perfectionism and the DSM-5 personality traits. Personality and Individual Differences, 64, 115-120. doi:10.1016/j.paid.2014.02.031

Stoeber, J., \& Corr, P. J. (2015). Perfectionism, personality, and affective experiences: New insights from revised reinforcement sensitivity theory. Personality and Individual Differences, 86, 354-359. doi:10.1016/j. paid.2015.06.045

Uysal, R. (2015). Social competence and psychological vulnerability: The mediating role of flourishing. Psychological Reports, 117, 554-565. doi:10.2466/21.PR0.117c18z2

Young, C., LaMontagne, L., Dietrich, M., \& Wells, N. (2012). Cognitive vulnerabilities, negative life events, and depressive symptoms in young adolescents. Archives of Psychiatric Nursing, 26, 9-20. doi:10.1016/j.apnu.2011.04.008 